INTERNATIONAL JOURNAL OF MULTIDISCIPLINARY RESEARCH AND ANALYSis

ISSN(print): 2643-9840, ISSN(online): 2643-9875

Volume 04 Issue 06 June 2021

DOI: 10.47191/ijmra/v4-i6-05, Impact Factor: 6.072

Page No.- 712-719

\title{
Employee Engagement: Reward Recognitions and Stewardship Program at Kohler Power Company (India)
}

\author{
Dr. Dipti Tulpule ${ }^{1}$, Dr. Aparajita Dasgupta Amist ${ }^{2}$, Prof Prashant Chougule ${ }^{3}$, Prof Mansi Jain ${ }^{4}$
}

\section{INTRODUCTION}

Employee engagement is the level of commitment and involvement an employee exhibits towards his/ her organization and its values. An engaged employee is aware of the business context and works with colleagues to improve performance within the job for the benefit of the organization. The organization must work to develop and nurture engagement, which requires a twoway relationship between employer and employee'. Thus, employee engagement is a barometer that determines the scope, richness \& depth of the association of a person with the organization.

Employee engagement is a multidimensional concept considering the two-way interaction between the employers and employees of an organization. As a matter of fact, employee engagement has emerged as a notable need for businesses. Employee engagement is important for any employer who aims to retain their valued employees as an employer's capability to manage employee engagement is related to their ability to achieve enhanced business gains and high level of performance.

"People may forget words; people may forget actions; but people will always remember respect, recognition \& appreciation given to them publically for their contributions..."

The basic for the efficient functioning of a company is that its employees work hard and stay motivated no matter how tough the client is to deal with. This can only happen if the employees find a driving force towards working in a fulfilling way from within a company. And a company can reciprocate to its employees in no better way than rewards and recognition along with constant appreciation and most importantly, constructive criticism. These have been the reasons for the employees of any company to work better than they used to. By implementing different rewards and recognition, firms show that the employee has not gone unnoticed and that their work is dearly valued. This is the case study of Kohler Company, which has taken multiple initiatives under employee engagement. However, case study focuses mainly on two areas:-

1) Rewards and recognition

2) Stewardship program

Kohler Company, founded in 1873 by John Michael Kohler, is an American manufacturing company based in Kohler, Wisconsin. Kohler is best known for its plumbing products, and manufactures furniture, cabinetry, tiles, engines and generators. Destination Kohler also owns various hospitality establishments in the United States and Scotland.

Early products included cast iron and steel farm implements, castings for furniture factories, and ornamental iron pieces including cemetery crosses and settees. A breakthrough came in 1883 when John Michael applied enamel to a cast-iron horse trough to create the company's first bathtub. The company has been primarily in the plumbing business ever since, and is known for its plumbing fixtures.

In the early 20th century, Kohler made drinking fountains with a "bubbling valve", from which water shot vertically. Eventually the entire fountain came to be known as a "bubbler". The term bubbler is still used in most of Wisconsin and some other areas of the United States.

In 1998, Kohler made a plan to buy back any outstanding shares not owned by the family. All family members had to exchange their common shares for shares with limited rights that could not be sold. Since Kohler is not a publicly traded company, the number of shares floating was minimal. Kohler offered $\$ 55,400$ per share, but some shareholders challenged this valuation and sued. The IRS also challenged this valuation by prosecuting the estate of Frederick Kohler, who had recently died holding 975 shares, but Kohler won the lawsuit.

Kohler Co. Residential Review Committee reviews certain modifications to residential properties in the Village of Kohler to ensure compliance with planning concepts and architectural forms originally created by the Kohler Improvement Company. 
Employee Engagement: Reward Recognitions and Stewardship Program at Kohler Power Company (India)

\section{KOHLER POWER}

In 1920, Kohler introduced the first modern-day generators. Originally created to power KOHLER plumbing products in rural America, the KOHLER Automatic Power \& Light (powered by a KOHLER engine) provided instant electricity to homes, boats and businesses around the world.

Kohler establishes itself as one of the world's leading power providers in 1933, when Byrd made his second journey to the South Pole with KOHLER generators. He dug out and refueled the original 1929 generators from beneath snow and ice. In 1948, Kohler created its famous K-Series engines, the company's first stand-alone gasoline engines for lawn and landscape, agriculture and snowmobiles. The engines proved so reliable that many are still running to this day. In 1998, Kohler creates the world's first electronic fuel injection (EFI) engine for lawn mowers. This breakthrough technology provides commercial cutters with easier starts and significant fuel savings.

In 2005, Kohler became the third largest generator manufacturer. In 2007, Diesel Engines became a part of Kohler with the acquisition of Lombardini. In 2012, Kohler created the world's first Tier 4 diesel engine (KOHLER Diesel KDI) without a DPF. The revolutionary engine provided operators with a Tier 4 final solution and significantly lower operating costs, while offering OEMs maximum power in a more compact size. KDI won Diesel magazine's coveted "Diesel of the Year" award. Kohler came up with Decision-Maker 3500 marine controller. The world's first and only integrated paralleling system for marine generators. In 2015, Kohler launches the fuel-efficient Command PRO EFI 824 gas engine - the most powerful engine in its class.

Today, Kohler Power works in six Continents around the world and is well known for its Power engines. It believes in bringing change and outperforming itself each time. Cost, Customer focus and Right time thing is the basic principle Kohler follows to achieve success in its way.

\section{VISION}

"Our vision is to bring our products into the 21st century through innovation and modern technology. Through learning the need of our customers, we will improve our ability"

\section{Mission}

“345"

The above numbers mean:-Three times the engines sales, Four times the gensets sales, in five years' time

\section{VALUES}

Kohler follows four basic competencies which are considered as the core values of the company. It includes:

- Build Trust

- Set High Standards of Performance

- Drive Continuous Improvement

- Focus on the end Customer

Its main principle is to "be the change".

\section{PRODUCT}

KOHLER POWER - In Power Since 1920, have two main branches in India: Kohler India Corporation Private Limited and Lombardini India Private Limited. KICPL is in charge of two sectors: Kitchen \& Bath and Services for Gensets. LIPL deals with three sectors: Gensets manufacturing, Engines and ITC. Kohler Pune handles the services for Gensets and ITC department. Kohler power deals with the following Products:

- $\quad$ GENERATORS

- Home Generators - For domestic use. Run on propane or natural gas.

- Industrial Power System - Built for most critical jobs. Provide power to hospitals, data centers, airports, nuclear power plants and many more.

- Marine Generators - Commercial workboats or mega yachts, Kohler provides power even to the water vessels.

- Portable Generators - Carrying your power anywhere you want is important. Kohler provides portable generators to overcome the hindrance of immobility. Camping or facing a storm, it helps in all situation. 
Employee Engagement: Reward Recognitions and Stewardship Program at Kohler Power Company (India)

Few of the Product Model includes:

KKN04-II-3.5kVA, 3.5kW

KE30-II-30kVA, $24 \mathrm{~kW}$

- $\quad$ ENGINES

- Gasoline Engines - Designed to meet a variety of application needs. Kohler's Gasoline engines ranges from $3 \mathrm{hp}$ to $38 \mathrm{hp}$.

- Diesel Engines - Available in air- cooled, liquid- cooled and the new Kohler KDI, delivering the maximum power.

- Alternative Fuel Engines - with propane natural gas, flex fuel E85 and tri fuel options, the command pro engines meet the emission needs.

Few of the Product Model includes:

KDW702 - 17.0 HP

KDW1003-26.5HP

- UPSL

In today's $24 / 7$ on demand world, mission-critical business systems must be available $100 \%$ of the time. Downtime cannot be tolerated, which is where a UPS system can assist. At Uninterruptible Power Supplies Ltd. We pride ourselves on delivering industry-leading power protection solutions combined with service excellence to ensure our UPS power supplies are 'Always On'.

- $\quad$ PARTS and SERVICES

- Customize your Equipment

- Maintenance and Service Parts

- Services and Technical Support

- Global Parts Distribution

Kohler Generators range from 3.5 kVA to 4200 kVA.

\section{ACQUISITION AND MERGERS}

- $\quad$ Kohler acquired, French- based SDMO industries in 2005.

- Other acquisition included- Italian engine leader, Lombardini in 2007

- World's premier power supply provider, Uninterruptible Power Supplies Ltd (UPSL) joins Kohler in 2008.

- Kohler further acquired, Brazilian-based generator company, Maquigeral in 2012

- Other Global Brands associated with Kohler Power include:

- Clark Energy

- BES

- Soreel

\section{FUTURE PLANS}

- To transform India into the export hub in future

- To maintain double digit growth in India

- Aurora healthcare to open a hospital in the village of Kohler, a land owned by Kohler Co. in Wisconsin, USA

- To increase market share in genset \& engines business in India

\section{CORPORATE OBJECTIVE}

Support the business to attain the leading unit and value market share in every market or market segment in which we participate.

\section{BELIEFS}

Kohler Co. was founded in 1873 and remains one of America's oldest and largest privately held companies. Our story is one of entrepreneurial spirit, passion, tenacity, determination, and a deep belief in this country and our organization to persevere and grow. Over the course of the last 143 years, Kohler has been built by the hard work of many associates and has survived 18 recessions, two depressions and the most recent global economic crisis. Kohler Co. today has never been in a stronger financial or strategic position. 


\section{Employee Engagement: Reward Recognitions and Stewardship Program at Kohler Power Company (India)}

We stay focused on controlling what we can control - practicing our mission of enhancing the level of gracious living for all those touched by our products and services, pursuing our guiding principles, reinvesting over 90 percent of our earnings back into the business every year, and trying to leave the world a better place than we found it.

\section{STEWARDSHIP}

WE BELIEVE that the path to a better place is a constant endeavor. Every day over 30,000 Kohler associates worldwide are moving forward with a focus on sustainability and stewardship. Some strides are larger than others. But what's most important is that steps are being taken in a positive direction. And that's a really big deal.

WE BELIEVE that you should join us on our journey. And whatever you believe in doing, no matter how big or small, if it makes our world a better place, it's a belief that Kohler can get behind.

That's the spirit of \#BelievinginBetter.

\section{REWARDS AND RECOGNITION}

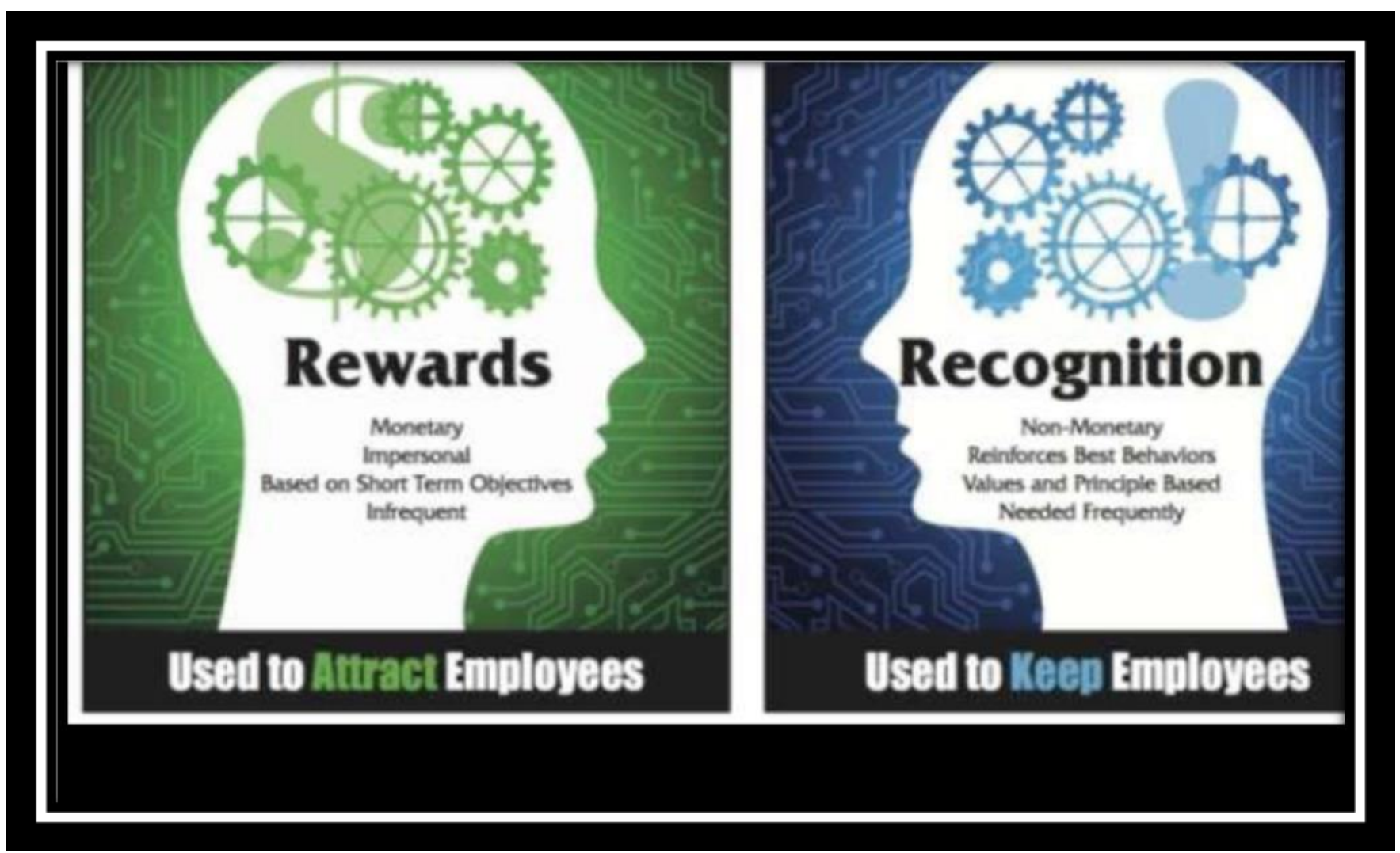

"Rewards and recognition are fine; but they should be focused on showing people that we truly appreciate their efforts."

In a competitive market, more business owners are looking at development in quality while reducing costs. This system deals with the assessment of job values, the plan and management of pay arrangement, performance management; pay for performance, competence or skill, the provision of employee benefits and pensions. Importantly, a reward and recognition system is also concerned with the development of appropriate managerial cultures, foundation core values and increasing the motivation and commitment of employees. Reward system processes cover both financial and non-financial rewards.

\section{EMPLOYEE REWARD AND RECOGNITION SYSTEMS}

In a competitive business climate, more business owners are looking at improvements in quality while reducing costs. Meanwhile, a strong economy has resulted in a tight job market. So, while businesses need to get more from their employees, their employees are looking for more out of them too. Employee reward and recognition programs are one method of motivating employees to change work habits and key behaviors to benefit a business.

\section{REWARD VS. RECOGNITION}

Although these terms are often used interchangeably, reward and recognition systems should be considered separately. Employee reward systems refer to programs set up by a company to reward performance and motivate employees on individual 


\section{Employee Engagement: Reward Recognitions and Stewardship Program at Kohler Power Company (India)}

and/or group stage. They are usually considered separate from salary but may be monetary in nature or otherwise have a cost to the business. While previously considered the area of big companies, small businesses have also begun employing them as a tool to lure top employees in a competitive job market as well as to increase employee performance.

Employee recognition programs are often combined with reward programs they retain a different idea altogether. They are planned to provide a psychological reward. Though many elements of scheming and maintaining reward and recognition systems are the similar, it is helpful to keep this disparity in mind, particularly for business owners interested in motivating staffs while observance costs low.

Rewards and recognition are powerful tools for employee motivation and performance improvement.

A reward is something given to a person or a group of people to recognize their excellence in a certain field; a certificate of excellence. Awards are often signified by trophies, titles, certificates, commemorative plaques, medals, pins, or ribbons. An award may carry a monetary prize given to the recipient.

Recognition is public acknowledgement of person's status or merits (achievements, virtues, service, etc.) When some person is recognized, he or she is accorded some special status, such as a name, title, or classification.

\section{IMPORTANT FACTORS IN A RECOGNITION PROGRAM}

1. The recognition program does not exclude any employee.

2. The employees know exactly what should be accomplished in order to earn recognition and rewards.

3. The manager's success is tied to employee's success.

\section{PROGRAM PURPOSES}

1. Recognize individuals and teams in a timely and effective way.

2. Provide a continuum of opportunities to acknowledge and recognize members of the organization.

3. Recognize that each individual can make a difference.

4. Be a fair and flexible practice that is woven into the fabric of the organizational culture.

\section{IMPACT OF RECOGNITION PROGRAM}

\begin{tabular}{|c|c|c|}
\hline TO SENIOR MANAGEMENT & TO EMPLOYEES & TO MANAGERS OF PROGRAM \\
\hline $\begin{array}{l}\text { 1) Increase Productivity. } \\
\text { 2) Improve attitudes } \\
\text { 3) Build loyalty \& Commitment. } \\
\text { 4) Generates positive feedback. } \\
\text { 5) Empower workforce. } \\
\text { 6) Assures efficiency }\end{array}$ & $\begin{array}{l}\text { 1) Satisfied recognition needs. } \\
\text { 2) Creates positive recognition } \\
\text { Experience } \\
\text { 3) Builds belongingness and loyalty }\end{array}$ & $\begin{array}{l}\text { 1) Efficient administration } \\
\text { 2) Employee excitement and } \\
\text { relations } \\
\text { 3) Involves all Employees } \\
\text { 4) Develops a partnership with the } \\
\text { workforce }\end{array}$ \\
\hline
\end{tabular}

\section{KOHLER REWARD \& RECOGNITION}

Kohler Company has three type of reward system for the employees.

- YAA award (You are appreciated Program)

- YAA award is you are appreciated award, and it has a YAA card also.

- This award is linked with the core competency.

- This is for individual as well as cross functional teams.

- Any employee can give the YAA Card to any employee irrespective of the levels of hierarchy.

- There are bronze, silver and gold awards.

- Bronze card is given for spot recognition,

- Silver award is by quarterly review of the Bronze nominations and

- Gold award is given for Annual recognition through review of quarterly silver award winners by a predecided assessment panel.

○ Kohler rewards them through gift cards of specific denominations 


\section{Employee Engagement: Reward Recognitions and Stewardship Program at Kohler Power Company (India)}

- $\quad$ Functional excellence award

- Functional excellence award is given to a function (team) which meets the targets for the financial year.

- Long service award

- Long service award is given to employees who complete 5 years, 10 years, 15 years, 20 years and 25 years in the company.

○ These employees are recognized through reward of personalized Kohler Silver Coin.

\section{REWARDS AND RECOGNITION}

The Reward and Recognition $(R+R)$ Framework supports our culture statement: 'Confident people working together for the future' it is an integral part of the People and Culture Strategy and achievement of its five key objectives:

1. Sustainable Organisation

2. High Performance Culture

3. Innovative Workforce

4. Transforming Leadership

5. Great Place to Work

A reward is defined as something which is given following the occurrence of certain behaviour, with the intention of acknowledging the positive nature of that behaviour, and often with the additional intent of encouraging it to happen again. Rewards can be intrinsic or extrinsic in nature. Intrinsic rewards are internal to the individual, such as contributing to a common good, mentorship or 'giving back'. Extrinsic rewards are rewards external to the individual, such as payments and promotions (tangible) or praise and public recognition (intangible). This $\mathrm{R}+\mathrm{R}$ Framework provides a range of strategies to cater for different preferences, levels of achievement and values.

\section{PRINCIPLES}

All rewards should:

1. Motivate and reward a high-performance culture.

2. Promote a close link between performance, reward and recognition.

3. Reward significant and outstanding performance that advances EPA's goals and values.

4. Provide timely recognition for individual and team achievement.

5. Provide rewards that are valued and meaningful to staff.

6. Be fair, applied consistently and transparent.

7. Be simple to understand and apply.

8. Be clearly communicated to staff.

\section{STEWARDSHIP}

Stewardship is an ethic that embodies the responsible planning and management of resources. The concepts of the stewardship can be applied to the environment, economics, health, property, information, etc.As a socially alive and conscientious corporate citizen, Kohler Power India Pvt Ltd. is committed to empowering the society through regular initiatives.

\section{Corporate Social Responsibility?}

Corporate Social Responsibility (CSR) is a business approach that contributes to sustainable development by delivering economic, social and environmental benefits for all stakeholders.

\section{Why is Corporate Social Responsibility Important to Kohler Co.?}

- Improves recruitment and retention

- Improves Associate engagement

- Increases brand preference and loyalty

- Channels Corporate Giving to reach programs and locations that provide the most impact Enables global sharing of ideas.

\section{Benefits for businesses}

Business transformation and sustainable approach to management translate into: 


\section{Employee Engagement: Reward Recognitions and Stewardship Program at Kohler Power Company (India)}

- Identification of the areas that create the organization's long-term value

- Reduction of operating costs due to more effective resource management across the entire supply chain

- Effective economic, social and environmental risk management

- Business stability relying on good relations with key stakeholders

- Building loyalty and trust of customers through a dialogue and engagement

Sustainability is a response to the challenges of the modern world which transforms potential threats and risks into development opportunities for organizations from the public and private sectors.

\section{CORPORATE SOCIAL RESPONSIBILITY/STEWARDSHIP PROGRAM}

- Kohler Company called the CSR as stewardship, believing in better. It has four pillars; they are community, sustainability, work place and arts. In community it is for society, voluntary works, donation, local partnership. Sustainability is foot print reduction, product innovation, education awards. Workplace is ethics, safety, wellness, encouragement, talent development. Arts/industry is craftsmanship, product innovation. The company has regional wise stewardship teams that undertake activity or programmes under these four pillars.

\section{CORPORATE COMMUNICATION}

- Company conduct quarterly town halls for all its associates or employees. The quarterly town halls cover financial highlights, the achievements and learning's, functional updates and recognition of the quarterly winners. Apart from that any updates, news or changes in policy are conveyed through emails

\section{FAMILY BENEFITS}

- Company provides medical insurance for the employees, their spouse and two children who are dependent up to 25 years of age. Additionally employees can opt to avail insurance for parents or parents in law at an additional premium.

\section{GRATUITY}

- The gratuity is paid to employees at the time of separation / retirement at the rate of $4.81 \%$ of the basic salary, if the employee has worked with the company for more than 5 consecutive years.

\section{EMPLOYEE RETENTION ACTIVITYS}

- The retention activities are birthday celebrations of the employee, wellness camps, employee wellness programmes, yoga training, and festival celebrations. Then taking the employees and their family for movies.

- Incentives and performance bonus availability across all levels, role and functions.

- Variety of programmes to recognize and appreciate different categories of employees for different types of tasks, behaviour's, efforts, achievements for which they are recognized.

- Recognition and celebrations are done for not only work related efforts and achievements/ results, but for achievement which are beyond work as well.

- Nomination form mails are sent to all managers.

The commitment of business to contribute to sustainable development, commonly understood as sustainable development is the ability of the current generation to meet its need without compromising the ability of future generations to meet theirs. Conclusion Based on the thoughtful study of the researches being conducted with employee engagement at the centre, the researcher concludes that it is emerging as an important HR concept. Employee engagement is soon going to become one of the prime HR function. The researchers understanding of the concept says that it is related to employee's attitude, how they feel about their jobs and the organization they are working with. Also, it is about the commitment or the emotional attachment which an employee shares with the organization. And the commitment is a result of satisfaction which the staff gets from the overall functionality of an organization including good working condition, good leaders, role and goal clarity, clear and accessible policies. Engaged employees are more satisfied and are more likely to stay with their organization as a result of that commitment. The performance curve of organizations with highly engaged employee's moves in upward direction and is smoother. Engagement is a great predictor of future financial performance; it affects business outcomes as well. Engagement drives up profits in turbulent conditions. The contribution of employees in terms of enhanced performance helps an 


\section{Employee Engagement: Reward Recognitions and Stewardship Program at Kohler Power Company (India)}

organization to win over difficult times. Employee engagement is related to meaningful business outcomes. Engaged employees enable successful implementation of business strategies, they fuel higher levels of business performance. Fully engaged workforce is loyal, and will align their efforts with organizational goals to remain in competition

\section{REFERENCES}

1) https://www.ambitionbox.com/benefits/kohler-benefits

2) https://sweetfishmedia.com/show/crafting-culture/the-1-tool-for-negotiating-employee-benefits-w-ryan-kohler/

3) https://www.payscale.com/research/IN/Employer=Kohler\%2C_Co./Benefits

4) Agrawal, S., \& Ojha, R. P. (2016), “Employee engagement in new business horizon,” (Article in Press). Agrawal, S. (2015), "Predictors of employee engagement: A public sector unit experience", Strategic HR Review, 14(1/2), pp. 57-68.

5) Brown, S. P. (1996), “A meta analysis and review of organizational research on job involvement," Psychological Bulletin, 120(2), pp. 235-255.

6) Gilbert, J. (2011), "The Millennial: A new generation of employees: A new set of engagement policies," Ivey Business Journal

7) Simon AL. ?e in?uence of job, team and organizational level resources on employee well-being, engagement, commitment and extra-role performance Test of a model. International Journal of Manpower. 2012; 33(7):840-53.

8) Vishal G, Sushil K. Impact of performance appraisal justice on employee engagement: a study of Indian professionals. Employee Relations. 2013; 35(1):61-78.

9) Christensen HL, EvelinaR. Talent management: A strategy for improving employee recruitment, retention and engagement within hospitality organizations. International Journal of Contemporary Hospitality Management. 2008; 20(7):743-57. 